University of Nebraska - Lincoln

DigitalCommons@University of Nebraska - Lincoln

U.S. Department of Veterans Affairs Staff

Publications

U.S. Department of Veterans Affairs

6-29-1996

\title{
Lethal infection by a previously unrecognised metazoan parasite
}

\author{
Mónica Santamaría-Fríes \\ Kaiser-Permanente Medical Center \\ Luis Felipe Fajardo \\ Stanford University School of Medicine \\ Mitchell L. Sogin \\ Marine Biological Laboratory, sogin@mbl.edu \\ Peter D. Olson \\ University of Connecticut - Storrs \\ David A. Relman \\ Stanford University School of Medicine, relman@stanford.edu
}

Follow this and additional works at: https://digitalcommons.unl.edu/veterans

Santamaría-Fríes, Mónica; Fajardo, Luis Felipe; Sogin, Mitchell L.; Olson, Peter D.; and Relman, David A., "Lethal infection by a previously unrecognised metazoan parasite" (1996). U.S. Department of Veterans Affairs Staff Publications. 14.

https://digitalcommons.unl.edu/veterans/14

This Article is brought to you for free and open access by the U.S. Department of Veterans Affairs at DigitalCommons@University of Nebraska - Lincoln. It has been accepted for inclusion in U.S. Department of Veterans Affairs Staff Publications by an authorized administrator of DigitalCommons@University of Nebraska - Lincoln. 


\title{
Lethal infection by a previously unrecognised metazoan parasite
}

\author{
Mónica Santamaría-Fries, Luis Felipe Fajardo L-G, Mitchell L Sogin, Peter D Olson, David A Relman
}

\section{Summary}

Background New microbial pathogens or variant clinical manifestations of known organisms may be first found in immunodeficient patients. An HIV-infected man developed a rapidly-enlarging abdominal mass, suggestive of a neoplasm, that subsequently invaded his liver and caused death. Initial studies showed unusual tissue morphology that could not be matched with any known disease process.

Methods Tissues obtained from biopsy at laparotomy and necropsy were studied by light microscopy, immunohistochemistry, electron microscopy, and broadrange ribosomal DNA-amplification and sequence analysis.

Findings Tissue lesions were characterised by peculiar cytoplasmic sacs containing minute cells with very prominent nucleoli. The pathological process was recognised as a parasitic infection, although its features were different from those of any known eukaryotic pathogen. Phylogenetic analysis of a 357 bp $18 \mathrm{~S}$ rDNA sequence amplified directly from the involved tissue indicated that the causative agent was a previouslyuncharacterised cestode.

Interpretation Fatal disease produced by this newly recognised cestode may not be limited to immunodeficient hosts. Awareness of this metazoan infection may allow early diagnosis-by morphology and DNA sequence analysis-and perhaps successful treatment of subsequent cases.

Lancet 1996; 347: 1797-1801

\section{Introduction}

HIV infection and AIDS have drawn attention to a number of previously unknown opportunistic infections. Some of the infectious agents have resisted classification or propagation in the laboratory. Parasitic infections contribute to the morbidity and mortality associated with HIV infection ${ }^{1,2}$ and atypical parasite behaviour and clinical presentations have been associated with immunosuppression. ${ }^{3,4}$ We encountered a micro-organism that caused a fatal illness in a patient with AIDS. This organism resisted identification until analysis of a small subunit ribosomal DNA (ss rDNA) sequence from infected tissue, indicated that the pathogen was a previously-uncharacterised plathyhelminth, probably a cestode.

\section{Patient and methods}

\section{Clinical history}

A 44-year-old man with HIV infection for 5 years and a recent diagnosis of AIDS (CD4+ cell count: $<100 \times 10^{-4} / \mathrm{L}$ ) was admitted to hospital in March, 1994, with a 2-month history of abdominal and low-back pain, weight loss, night sweats, and fever. During the previous 5 years, he had several upperrespiratory tract infections and episodes of diarrhoea but no specific opportunistic infection. Stool examination on two occasions was normal. Current medications were zidovudine, dapsone, and pentamidine. He had a previous history of hepatitis $B$ infection and treated syphilis. He had been in a monogamous homosexual relationship for 18 years. He worked as an accountant, lived in the San Francisco Bay Area, and had never travelled outside the USA. He went camping in the area in which he lived. He had two dogs with which he had close contact.

On admission he was febrile $\left(39^{\circ} \mathrm{C}\right)$. His abdomen was soft and non-tender; a periumbilical $8 \times 10 \mathrm{~cm}$ mass was palpable. An abdominal computed tomogram (CT) scan showed para-aortic, paracaval, and mesenteric nonhomogeneous lobulated masses, up to $9 \mathrm{~cm}$ long in their greatest dimension. A CT-directed biopsy yielded no diagnostic material. Colonoscopy and biopsies of rectum and terminal ileum were normal. The patient had an exploratory laparotomy and biopsy of the mesenteric mass 1 week after admission.

Because he was presumed to have a protozoan infection, metronidazole was started, but discontinued after 7 days due to intolerance. Severe abdominal pain persisted. He developed anaemia ( $\mathrm{Hb} 9.5 \mathrm{~g} / \mathrm{dL}$ ) and intractable nausea and vomiting with dehydration. He progressively deteriorated, and died 9 weeks after the laparotomy.

\section{Investigations}

Morphology Light microscopy and immunohistochemistry of paraffin-embedded samples from biopsy and necropsy material were done, and a biopsy sample was examined by transmission electron microscopy.

Ribosomal DNA sequence analysis Fresh-frozen liver tissue was divided into abnormal and normal portions by gross inspection. Segments of these two types of tissue measuring $3 \mathrm{~mm}^{3}$ were 


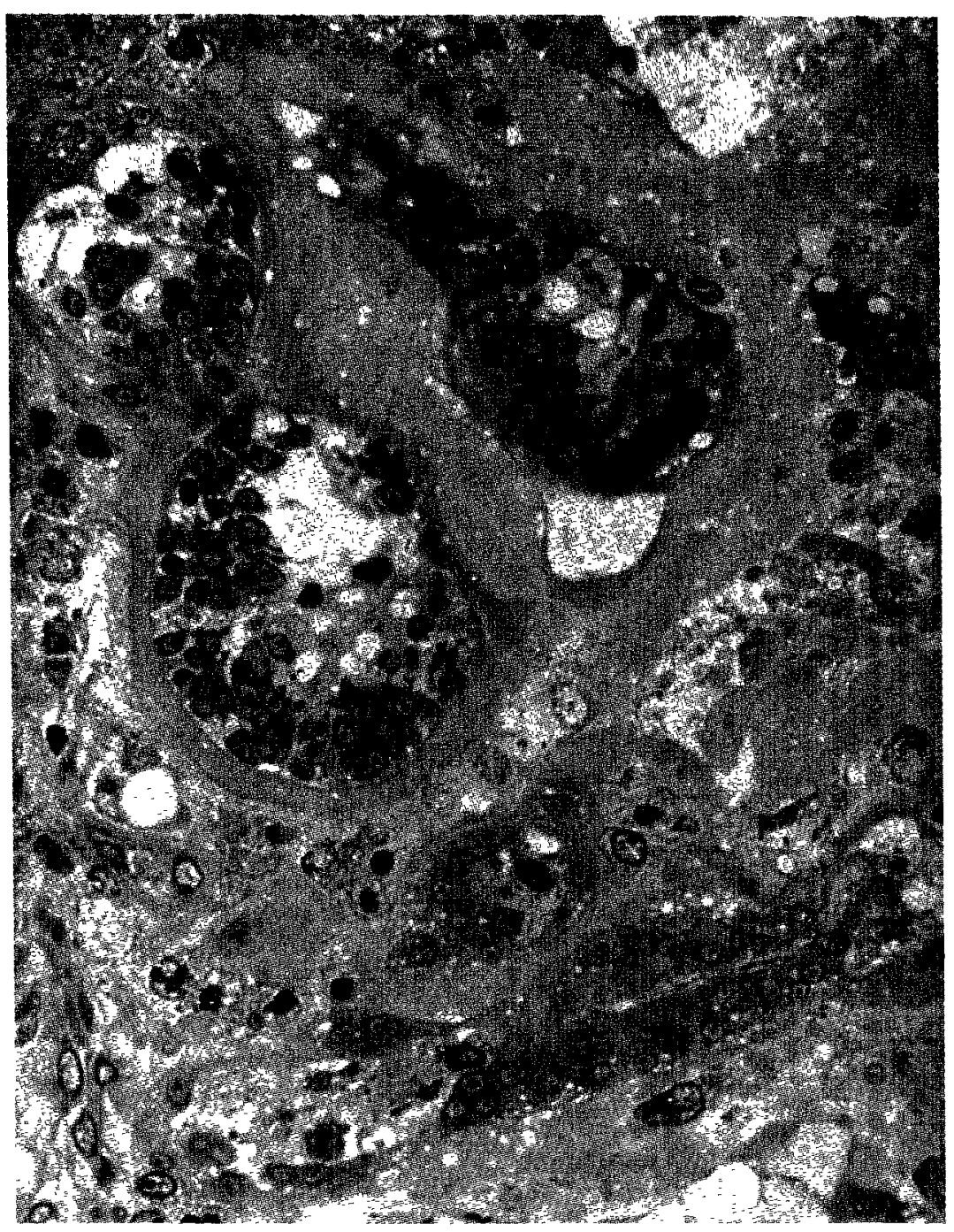

Figure 1: Paraffin section showing several parasitic sacs

Their wall (shell) stains poorly, contains few nuclei and varies considerably in thickness. The profiles of the sacs are oval, flaskshaped, or elongated. All sacs contain numerous cells which do not completely fill the lumına. In this field there are few inflammatory cells. Hematoxylin and eosin. $\times 320$.

digested and processed in parallel for PCR analysis. ${ }^{5}$ Broad-range eukaryotic ss rDNA amplification reactions included $20 \mathrm{pmol}$ of primers 1 FPL (Eukarya-specific,5'GCGGATCCGCGGCCGCTGGTTGATCCTGCCAGT 3') and 1520RPL (universal, 5'GCGGATCCGCGGCCGCYGCAGGTTCACCTAC 3'), $200 \mathrm{nmol} \mathrm{MgCl}_{2}, 2.5 \mathrm{U} T \mathrm{Taq}$ polymerase, and $1-10 \mu \mathrm{L}(1-10 \%)$ of the tissue digests in a total volume of $100 \mu \mathrm{L}$. With the hotstart technique, $40 \mathrm{PCR}$ cycles were done with an annealing temperature of $60^{\circ} \mathrm{C}$. PCR products were purified and sequenced directly with the Dye Deoxy Terminator Cycle Sequencing Kit (Perkin-Elmer, Foster, City, CA, USA). The ss rDNA sequence obtained in this study was aligned against a database of 80 eukaryotic ss rDNA sequences according to conserved primary and secondary structures. Phylogenetic analyses were based upon comparisons of 303 sites that were judged by these criteria to be in alignment. Phylogenetic trees were constructed with two algorithms: maximum parsimony using the software package PAUP3.1.1; and maximumlikelihood. ${ }^{8}$ Bootstrap values for the dendrogram generated by PAUP were obtained from 100 resamplings. Distance-matrix analysis followed the least squares method. ${ }^{9}$

\section{Results}

\section{Morphology}

The open-biopsy material of the mesenteric mass consisted of dense fibroadipose tissue within a rim of lymphatic tissue with an extensive inflammatory reaction characterised by fibrinous exudate, macrophages, and scattered groups of neutrophils forming microabscesses. There were no granulomas or eosinophils.

Randomly dispersed in this stroma were numerous

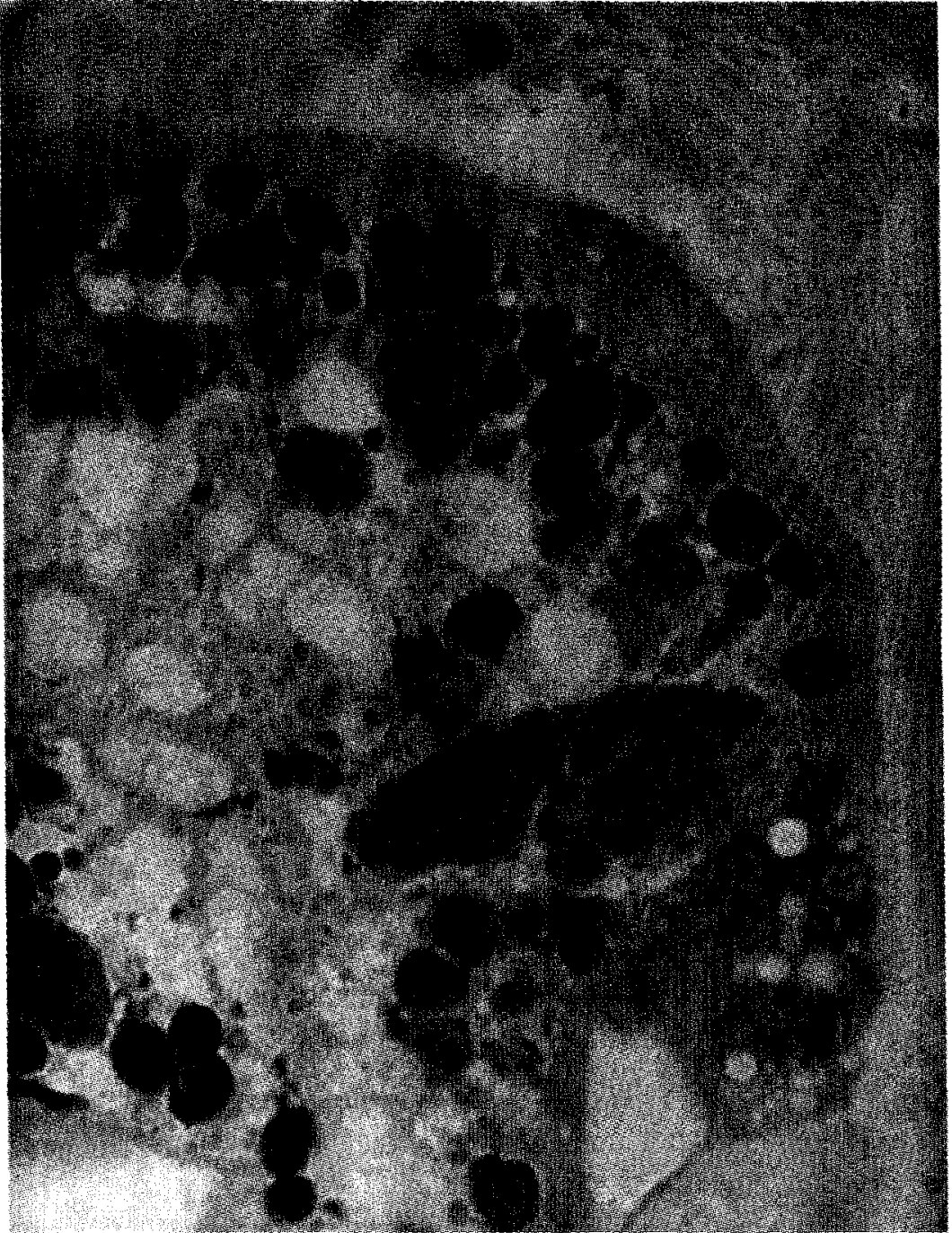

Figure 2: Portion of a parasitic sac

The gray-blue shell is acellular in the upper and right fields and contains some nuclel in the lower right. The peculiar cells with round, prominent nucleoli are concentrated on the inner aspect of the shell. Notice marked variation in cytoplasm density. Epon section stained with toluidine blue. $\times 800$

nests, or sacs, of the microorganism (figures 1 and 2). The sacs measured $85 \mu \mathrm{m}$ in average diameter, were oval or flask-shaped, and composed of an outer amphophilic shell (wall) that stained weakly with hematoxylin and eosin, and a central cavity containing characteristic cells. These cells had a mean diameter of $6.7 \mu \mathrm{m}$; their cytoplasm was dense and their most prominent feature was a small spherical nucleus ( 2 to $4 \mu \mathrm{m}$; clearly smaller than most human nuclei) with a very large round nucleolus. Some parasitic cells were multinucleated. A few sacs had ruptured and their cells were loose in the surrounding stroma. Although invasion of the sacs by histiocytes or neutrophils was seen, phagocytosis was not.

The possible human origin of these cells was explored with immunohistochemical reagents for normal or neoplastic human antigens, including cytokeratins, human chorionic gonadotropin, alpha fetoprotein, epithelial membrane antigen, $\mathrm{S}-100$ protein, vimentin, desmin, and multiple lymphoid markers. All of these markers were negative. The cells did not react with the usual stains for bacteria (such as Gram) or fungi (silver methenamine, Gridley etc). They were acid-fast negative (Ziehl-Neelsen) and did not contain acid mucopolysaccharides (with Alcian blue at $\mathrm{pH}$ 1.5). Although the cells were periodic acid-Schiff (PAS)-negative there was abundant PASpositive and diastase-sensitive amorphous material, presumably containing glycogen, among the cells.

Electron microscopy of the biopsy sample showed that the wall of the sacs was composed of cytoplasmic material containing some glycogen and a few nuclei (figure 3 ). The 


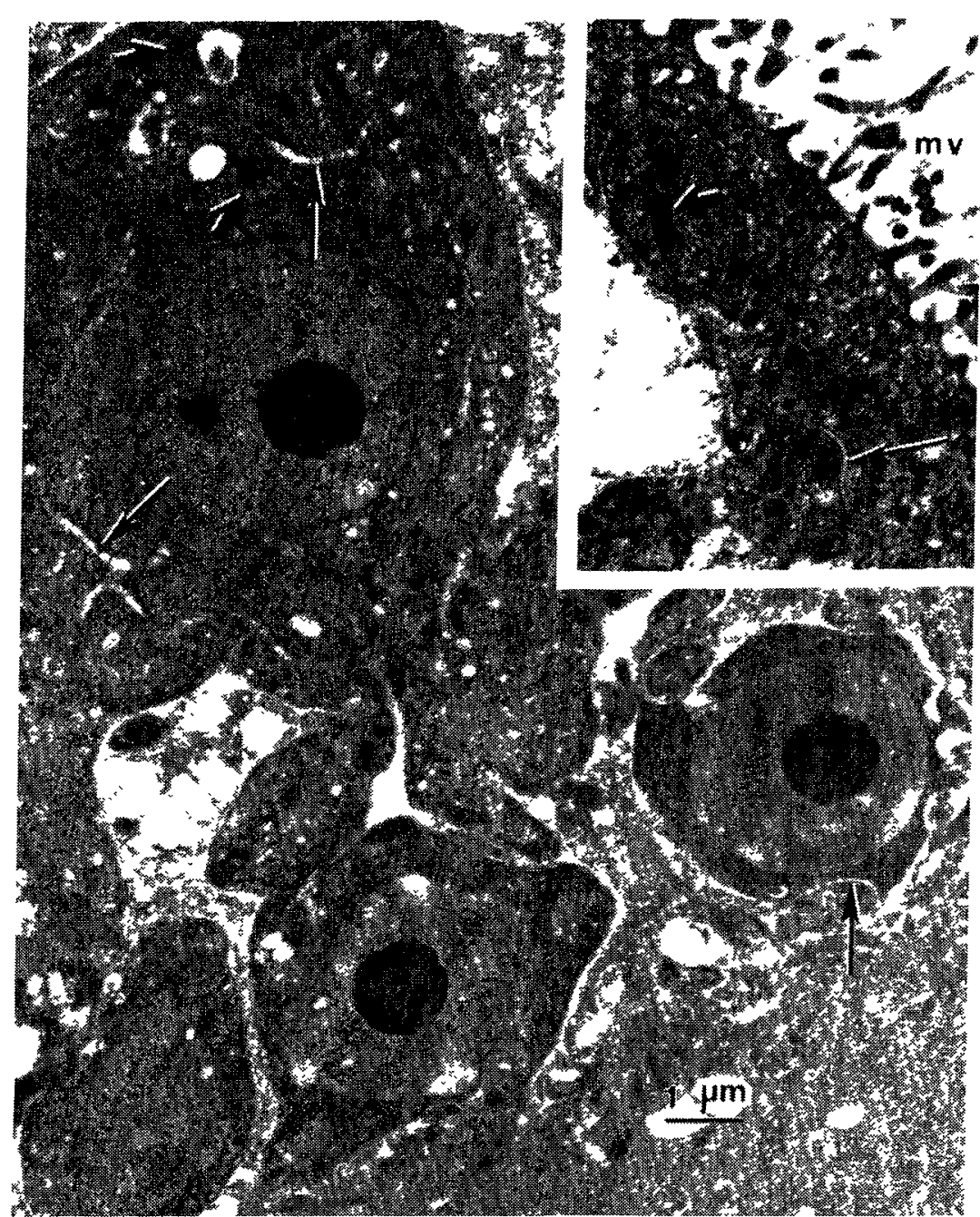

Figure 3: Ultrastructure of the large (upper left) and small (lower field) parasitic cells described in figs 1 and 2

The large - presumably immature - cell has small, Inconspicuous mitochondria (wide arrows) and multiple flat saccular structures with septations (long arrows). In the smaller cells-presumably older - the saccular structures have become thin channels and the cytoplasm is condensed. Uranyl acetate and lead citrate, $\times 6250$. The inset shows a section of the shell, made of cytoplasm containing a few mitochondria and a septated flat saccular structure. The elongated microvilli (mv) are seen on the outer, convex, aspect. Uranyl acetate and lead citrate. $\times 15000$.

outer surface of the wall was studded with a continuous layer of microvilli, while the inner surface projected lamellipodia toward the lumen. Inside the sacs were the minute cells seen by light microscopy. Those cells in the periphery, between lamellipodia, seemed to originate from

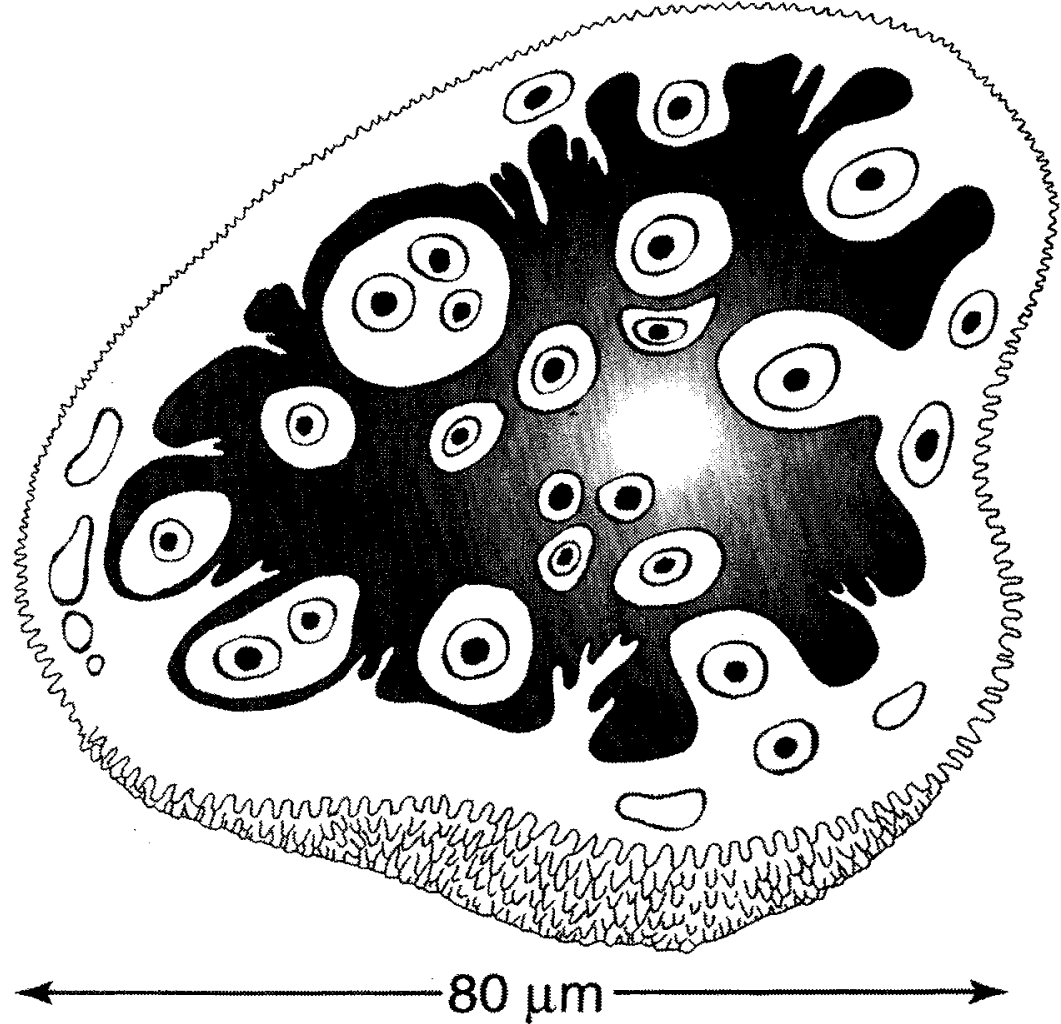

Figure 4: Three-dimensional reconstruction of a parasitic sacsectioned in the middle-based on light and electron microscopy

The cut surface is facing up, while the external surface, studded with microvilli, is partially seen at the bottom. The size of the microvilli has been exaggerated to make them visible at this magnification. The (cytoplasmic) wall contains some nuclei (right and top) and a few vacuoles (left). Within the sac are the characteristic cells, which appear to originate in the wall, detach from it and migrate toward the lumen, becoming smaller and denser in the process. The irregular projections of the wall's cytoplasm toward the lumen (lamellipodia) may serve to support the cells, or may represent the sites of separation of the cells from the common cytoplasm.

the wall and often were continuous with it. They had loosely distributed, small mitochondria and were larger than the cells closer to the centre of the sacs. Those cells in the center had denser cytoplasm, suggesting a process of maturation and/or senescence from the periphery to the centre of the sacs. All cells lacked rough endoplasmic reticulum, phagolysosomes, and junctional complexes (figure 4). Neither cell wall nor chloroplast were seen. Although these features suggested a metazoan parasite, there were no structures such as eggs, tegument, scoleces,

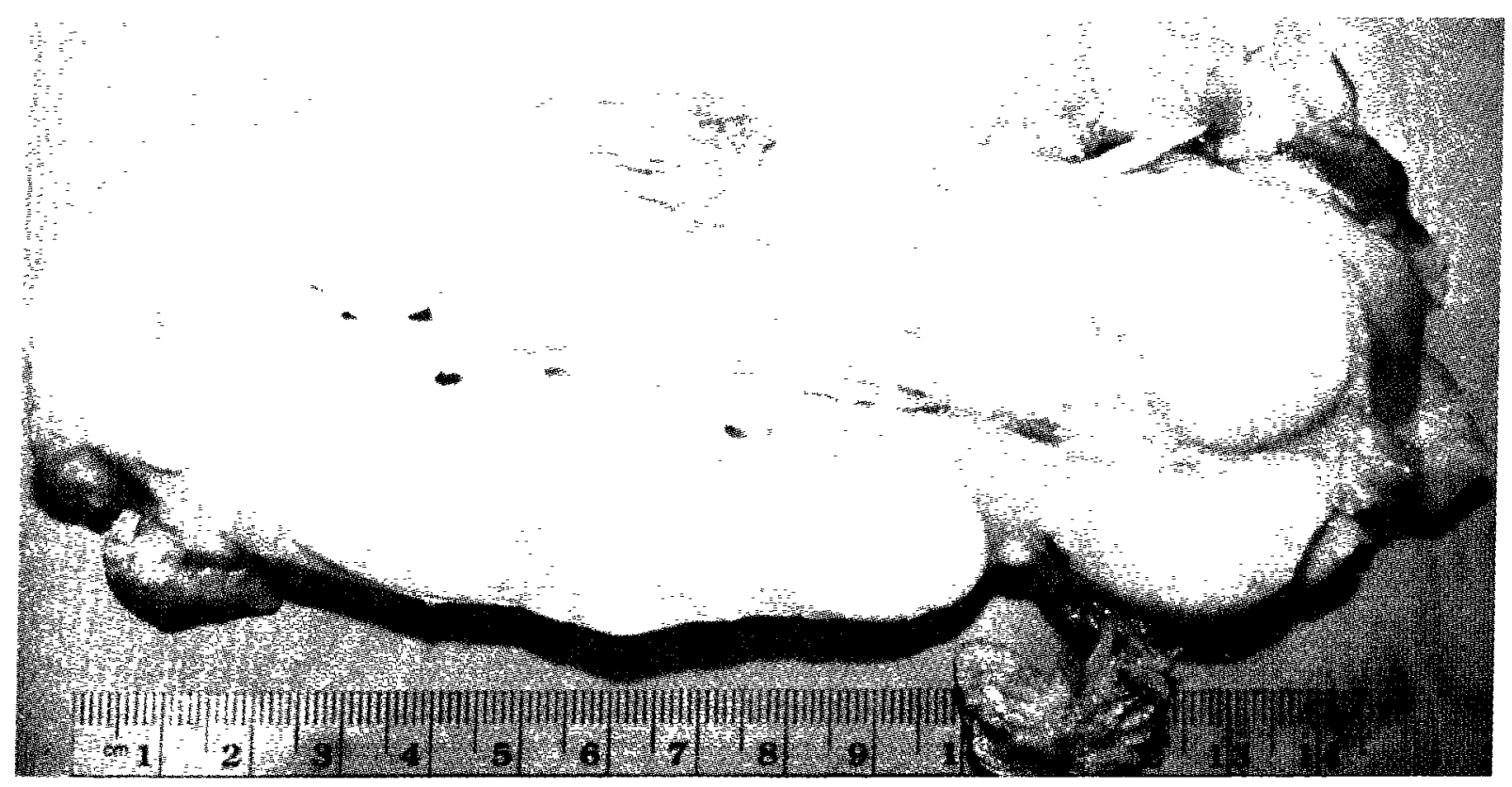

Figure 5: Section of the retroperitoneal mass

This large tan-white loblated tissue is composed of matted lymph nodes. The gross appeared closely resembles that of a neoplastic process such as a lymphoma. 


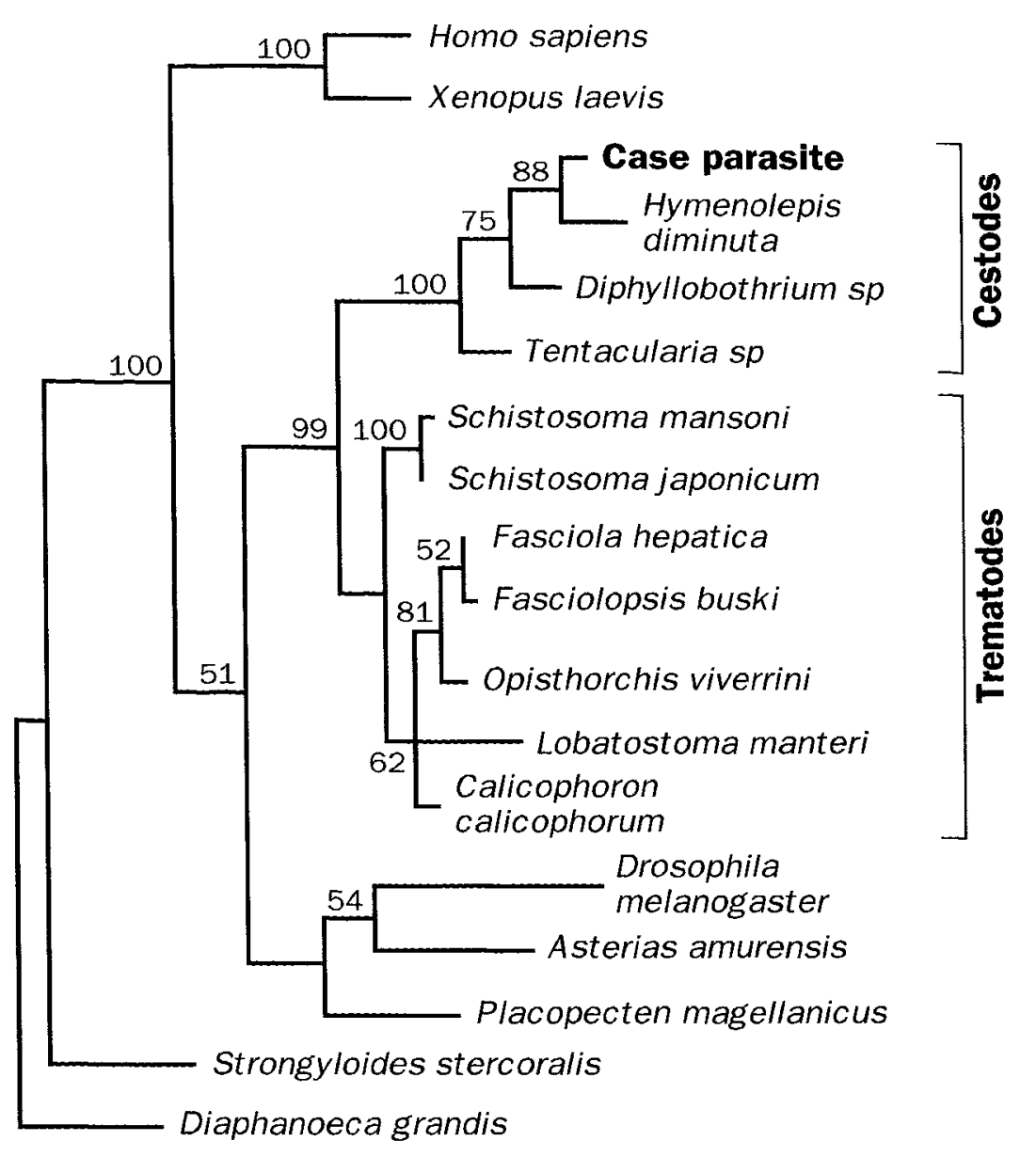

Figure 6: Phylogenetic tree based upon parsimony analysis of partial small subunit rDNA sequences

The analysis suggests that the case parasite is a cestode. This dendrogram represents the best tree among 100 bootstrap replic ates. The percentage of the 100 resamplings that corroborate the topology is given at branch nodes (only values greater than $50 \%$ are displayed).

or cilia.

Necropsy less than $6 \mathrm{~h}$ after death showed large mesenteric and retroperitoneal, lobulated tan masses, up to $20 \mathrm{~cm}$ in greatest dimension (figure 5). Smaller nodules were present in the diaphragm and lower retrosternal soft tissue. The liver, which was markedly enlarged, had bulky, irregular tan lesions that involved approximately $75 \%$ of the parenchyma. The abdominal masses and the liver had extensive necrosis and contained numerous plastic sacs, most of which were ruptured. Rare cytomegalovirus inclusions were observed in human cells within the mesenteric mass. There was severe bronchopneumonia. No evidence of cancer was found. Cultures from blood, liver, and mesenteric masses were negative for bacteria and fungi, except for light growth of Candida glabrata from one of the mesenteric samples.

\section{Small subunit rDNA analysis}

A PCR product of approximately $400 \mathrm{bp}$ was consistently detected in digests of diseased liver tissue with reactions using broad range Eukarya ss rDNA primers. No other PCR products were detected. On the other hand, digests of normal portions of liver from the same patient only yielded an approximately $1.8 \mathrm{~kb}$ PCR product (data not shown). A $1.8 \mathrm{~kb}$ DNA band would have been expected from amplification of human 18S rDNA with these primers. The disease-associated PCR product contained $357 \mathrm{bp}$, excluding the two PCR primers. This $357 \mathrm{bp}$ sequence corresponded to the ss rDNA of a previouslyuncharacterised metazoan (GenBank accession number U 58674). At approximate position 360 within the ss rDNA of the most closely-related organisms, there is a region in which 14 out of 15 nucleotides in a reverse complementary orientation match the $3^{\prime}$ end of primer $1520 \mathrm{RPL}$, suggesting that $1520 \mathrm{RPL}$ mispriming led to the amplification of this unexpectedly small DNA fragment. Parsimony, distance, and neighbour-joining phylogenetic analyses indicated that the case parasite is most closely-related to the cestodes (figure 6); bootstrap analysis strongly supported this association.

These results and the morphological data, suggest that the nests of cells represent a tissue-invasive larval stage of a cestode-like organism. Given the relatively few cestode ss rDNA sequences that were available for our analysis and the paucity of sequence data from the case parasite, we could not determine precise evolutionary relationships between this parasite and other cestodes.

\section{Discussion}

This patient had a progressive, tissue-destructive parasitic infection. Despite rigorous histological examination, the nature of the pathogen could not initially be identified. Efforts to detect signature elements and compounds in the diseased tissues by energy-dispersive and lipid-profile analysis (data not presented) failed to provide specific clues. Small subunit rDNA sequences allow the inference of phylogenetic relationships without reliance on cultivation or growth-based phenotypes. For this reason we amplified these sequences directly from infected tissue. Although there are very few cestode ss rDNA sequences available, our analysis suggests that this parasite is a previously-unknown cestode.

The lack of sequence similarity of this parasite with previously-characterised organisms is consistent with its unique histologic features. We have found no reports of a human-associated parasite morphology or clinical course that resemble those described in this case. In fact neither we, nor any of the experts on human and veterinary parasitic diseases we consulted, have seen this microorganism before. There is a vague similarity between this case and one reported by Connor et al in 1976 and interpreted as a possible embryonal stage of aberrant spirometra (sparganum). ${ }^{3}$ In one of their micrographs the minute cells and the enveloping sac slightly resemble our parasitic nests; other aspects, including the ultrastucture, are rather different. The morphology of this parasite suggests that it was in the larval stage..$^{3,11}$ No evidence of maturation (no change in morphology) occurred in the 3months between biopsy and death.

Assuming that this is a newly recognised human parasite infection, we could only speculate about the possible route of entry and its development within the host. Since the initially detected lesion was in the mesentery, infection through the mouth by eggs or larvae may have occurred, with subsequent penetration through the intestinal wall and dissemination into lymph nodes. The infection may have occurred either from ingestion of contaminated meats, fish, crustaceans, etc, containing procercoid larvae (as in the case of sparganosis) or ingestion of eggs or proglottids as in the case of taeniasis. ${ }^{12}$

As for the source, we have considered the possibility that the dogs with which the patient was particularly affectionate (to the point of biting their paws and noses) may have harboured the organism. Although no parasites were found in the dogs faeces, this source cannot be ruled out. The sexual partner of this patient is apparently healthy.

From studies in mice it appears that helper $T$ 
lymphocytes (especially the Th1 subtype) are important in the protective immunity against the cestode Hymenolepis nana. ${ }^{10}$ Thus, by analogy, this immunodeficient patient might have lacked selective protection against cestode infections.

Awareness of these unusual clinical and pathological features may allow early diagnosis and treatment in subsequent cases. Additional sequence-based studies may be necessary for the complete characterisation of this metazoan.

The authors greatly appreciate the expert opinions of the following persons: Jon Kosek, Michael Hendrickson, Tracy Tingle, Paul Basch, and Monte Laskosky (Stanford, CA); Daniel Connor (Washington, DC); Jack Frenkel (Santa Fe, NM); Daniel Gould (Fort Collins, CO); Eileen Johnson (Davis, CA); Govida S Visvesvara (Atlanta, GA) and David C White (Oak Ridge, TN). Helen Kwan, Kristine Yoder, Chris Morrow, and Donna Buckley provided technical assistance.

Supported in part by Veterans Affairs Research Fund FAJ004 (LFF), Lucille P Markey Charitable Trust (DAR), NIH Grant GM32964 (MLS), NSF (BSR-91-96213) (PDO), and University of Connecticut Research Foundation Grant awarded to C S Simon (PDO). DAR is a Lucille P Markey Biomedical Scholar.

\section{References}

I Gutierrez Y. Diagnostic pathology of parasitic infections with clinical correlations. Philadelphia: Lea \& Febiger, 1990.
2 Wittner M, Tanowitz HB, Weiss LM. Parasitic infections in AIDS patients. Cryptosporidiasis, isosporiasis, microsporidosis, cyclosporiasis. Inf Dis Clin North Am 1993; 7: 569-86.

3 Connor DH, Sparks AK, Strano AJ, Neafie RC, Juvelier B. Disseminated parasitosis in an immunosuppressed patient. Possibly a mutated sparganum. Arch Pathol Lab Med 1976; 100: 65-68.

4 Zumla A, Croft SL. Chemotherapy and immunity in opportunistic parasitic infections in AIDS. Parasitology 1992; 105: S93-101.

5 Relman DA, Schmidt TM, MacDermott RP, Falkow S. Identification of the uncultured bacillus of Whipple's disease. $N$ Engl f Med 1992; 327: 293-301.

6 Medlin L, Elwood HJ, Stickel S, Sogin ML. The characterization of enzymatically amplified eukaryotic 16 S-like rRNA coding regions. Gene 1988; 71: 491-99.

7 Swofford DL. PAUP: Phylogenetic analysis using parsimony, version 3.0s,. Champaign, IL: Illinois Natural History Survey, 1991.

8 Olsen GJ, Matsuda H, Hagstrom R, Overbeek R. fastDNAmL: a tool for construction of phylogenetic trees of DNA sequences using maximum likelihood. Comput Appl Biosci 1994; 10: $41-48$.

9 DeSoete $G$. A least squares algorithm for fitting additive trees to proximity data. Psychometrika 1983; 48: 621-26.

10 Asano K, Okamoto K. Murine 'T-cell clones specific for Hymenolepis nana: generation and functional analysis in vivo and in vitro. Int 7 Parasitol 1991; 21: 891-96

11 Berrada-Rkhami $\mathrm{O}$, Gabrion $\mathrm{C}$. The fine structure of the embryonic envelopes before and after hatching in bothriocephalids: physiological and ecological significance. Parasitol Res 1990; 76: 251-62.

12 Orihel TC, Ash LR. Parasites in human tissues. American Society of Clinical Pathologists. Chicago, IL, 1995. 